\title{
Optimization of The Machining Process OF NiCRBSi THERMAL SPRAYING
}

\section{Tomas Zatloukal, Jan Rehor, Jaroslava Fulemova \& Michal Povolny}
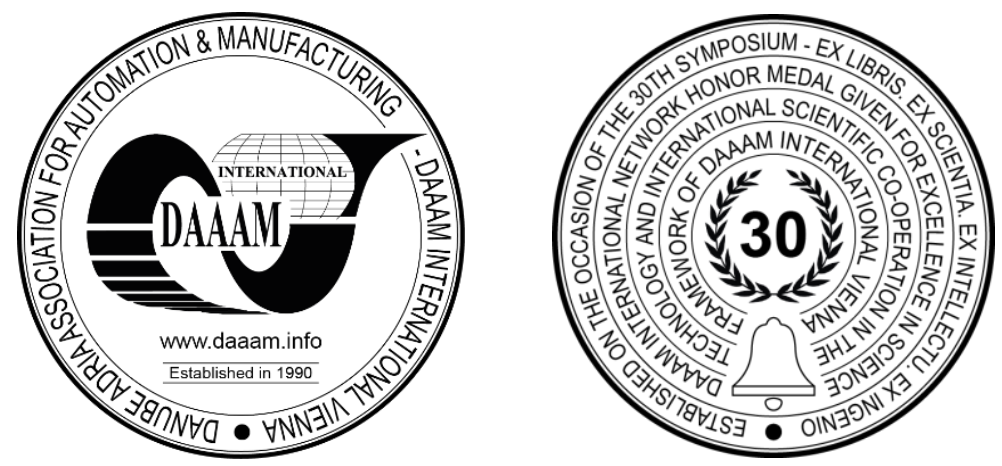

This Publication has to be referred as: Zatloukal, T[omas]; Rehor, J[an]; Fulemova, J[aroslava] \& Povolny, M[ichal] (2020). Optimization of the Machining Process of NiCrBSi Thermal Spraying, Proceedings of the 31st DAAAM International Symposium, pp.0632-0637, B. Katalinic (Ed.), Published by DAAAM International, ISBN 978-3-90273429-7, ISSN 1726-9679, Vienna, Austria

DOI: $10.2507 / 31$ st.daaam.proceedings.087

\begin{abstract}
Nowadays, the requirements for the properties of machine parts are increasing. With this trend, the application of thermal spraying is also growing. The main reason for the use of thermal spraying in industry is to increase the resistance to mechanical wear, corrosion and oxidation. At present, thermal sprays are machined using grinding technology due to their high hardness. The roughness Ra of the thermal spray after the application is around $7 \mu \mathrm{m}$. Such a large surface roughness is not very suitable for the functional purposes of the sprayed surface. Machining of the coating is therefore necessary to obtain less surface roughness and to achieve geometric and dimensional tolerances. The article describes the sequence and evaluation of the experiment in turning NiCrBSi thermal spraying under different cutting conditions. The effect of cutting speed and feed on the roughness value of the machined spray surface was investigated. Three types of cutting materials in the form of sintered carbide, cubic boron nitride and polycrystalline diamond were used for machining. The output was to find optimal cutting conditions depending on the surface roughness and the amount of insert wear.
\end{abstract}

Keywords: Thermal Spray; NiCrBSi; Surface Roughness; Machining; Cutting Conditions

\section{Introduction}

Coatings classified as thermal spraying are currently a widely used technology in many industries. Due to the everincreasing demands on machine parts, the effort is to continuously find new combinations of materials to increase reliability and better functional properties. Thermal spraying is characterized by high flexibility and reliability. The use of this technology in production also reduces the energy intensity of production and the associated production costs. The main reason for using thermal spraying is to increase resistance to mechanical wear, it also resists well to aggressive chemical environments, corrosion, oxidation, even in the case of elevated temperatures. [2] [5] [6] Thermal spraying is used, for example, in the automotive and aerospace industries, where it is applied to internal combustion engine parts as protection against wear at elevated temperatures. It can be mentioned, for example, various pins, pistons, cylinders, valves, crankshafts, etc. It also finds significant representation in the energy industry, where it is applied to turbine blades as a thermal barrier and protection against corrosion and cavitation. In the engineering industry, various types of thermal spraying are applied to components of pumping and hydraulic technology. 
Last but not least, certain types of thermal spraying are also used in the printing industry, where it is applied to heavily stressed surfaces of printing cylinders. [2] [4] [6] [12] The main principle of this technology is to create a thin coating on the base surface of the sprayed material. The layer is made of a special mixture of powder or wire with a certain chemical composition, which is fed into the combustion chamber. There, the individual particles of material are melted, are then accelerated in a special nozzle. These molten particles with high kinetic energy fall on the surface of the base material. After impact, the particles deform under the influence of high energy and form a continuous and very thin coating with a characteristic lamellar structure. Various combinations of alloys, steels, ceramics or pure metals are most often used for coating. [4] [6] [12]

Most of the thermal sprays produced are in the category of difficult-to-machine materials due to their specific composition. It contains many difficult-to-machine elements, such as nickel, chromium, tungsten and vanadium, which increase the hardness of these special alloys. These elements, together with carbon, also form very hard carbides in the microstructure, which cause intense blunting of the cutting edge during the machining process. It is for these reasons that grinding technology is mainly used to reduce the roughness on the sprayed surface. [3] [5] [10] [11]

Grinding of thermal sprays is time consuming due to the very small thicknesses of the cuts. There are also a number of complications associated with the grinding process that need to be considered. One of the problems is, for example, incorrectly aligned grinding wheel and failure to achieve good workpiece roundness. If the filter does not work properly, small particles of the removed material can get back into the cutting process by means of the cutting fluid. Possible problems can also arise from incorrect selection of the wheel for which the grain size, material and binder are selected. Due to the high speed of the tool, it is necessary to solve the possible occurrence of vibrations during grinding, etc. [3] [5] [11]

The article on Inconel 718 machining presents problems in finding optimal cutting conditions. A galvanically coated wheel developed especially for grinding Inconel 718 was chosen as the tool. Of the 14 combinations of different cutting conditions, the required surface roughness $\mathrm{Ra}=0.2 \mu \mathrm{m}$ was never achieved. Transverse corrugation was noted on the workpiece surface after grinding, see Figure 1. After a certain grinding time, gradual sticking of the grinding wheel also occurred, probably due to the large amount of nickel in the alloy. [10]
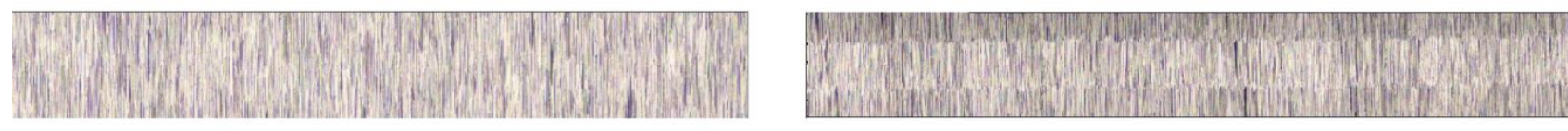

Fig. 1. Surface after grinding without / with transverse corrugation [10]

The roughness of the thermal spray after spraying is around $\mathrm{Ra}=7 \mu \mathrm{m}$. Such a large surface roughness is not very suitable for the functional purposes of the sprayed surface. Subsequent machining of the coating is required to obtain less surface roughness and to achieve geometric and dimensional tolerances. Machining is also affected by a change in surface integrity, which includes, for example, the adhesion of the formed coating, the hardness and strain hardening, or the residual stresses. Due to the very small thicknesses $(0,5-2 \mathrm{~mm})$ of the thermal sprays, there is a problem with the size and depth of the affected layer, as shown in Figure 2. [8] [9]

(1)
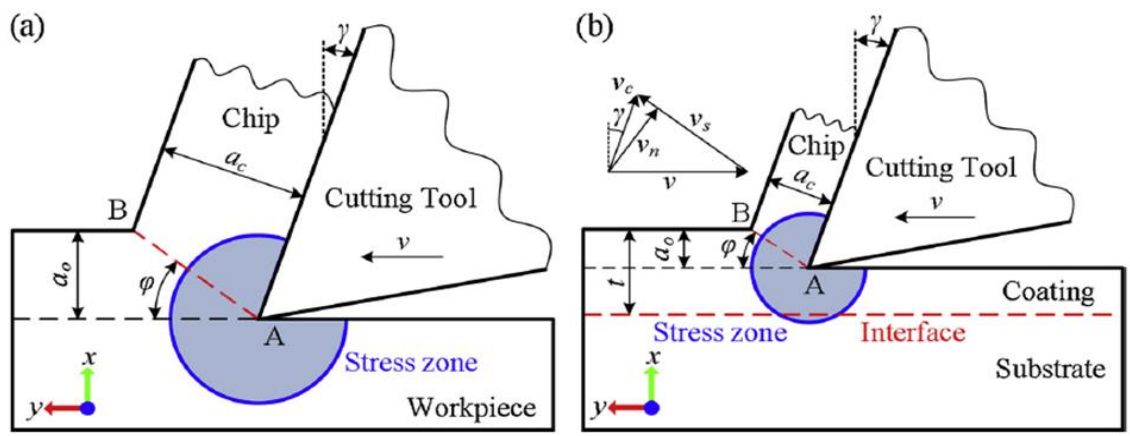

Fig. 2. Deformation during machining of solid material vs thermal spraying [8]

Critical cutting conditions occur during machining, when plastic deformation extends into the area of the base material. By inducing plastic deformation to such a depth, it can result in cracking or partial tearing of the thermal spray. For this reason, spraying is characterized by machining with a very small depth of cut in the range of $0.1-0.5$ $\mathrm{mm}$. On the other hand, it is necessary to observe the machining condition, such that the set depth of the cut must be higher than the radius of curvature of the cutting edge. [1] [8] [9]

At present, thermal sprays are machined using grinding technology due to their high hardness. The main goal of this research is to replace grinding technology with turning technology. The advantage of this change is the higher productivity of machining. At the beginning of this research, it was first necessary to find out whether we are able to obtain the same surface quality result as after grinding by the method of turning. 


\section{Materials used and methodology of the experiment}

\subsection{Materials used}

The four-component NiCrBSi alloy is characterized by very good wear resistance (Table 1). It also resists corrosion and cavitation erosion well. Regarding the materials used, this alloy can be classified in a category that has a low impact on the environment. The dominant element in this alloy is nickel, this thermal spraying can be included in the category of nickel alloys. The nickel just mentioned gives the alloy its specific properties in the form of resistance to abrasion, oxidation, corrosion, even at elevated temperatures. Chromium is the second element that is strongly present in the alloy. Together with nickel, it increases the already mentioned resistance to corrosion and oxidation. Besides, chromium significantly increases the hardness of this alloy by forming chromium precipitates. An important element in the $\mathrm{NiCrBSi}$ alloy is carbon, which together with chromium forms very hard carbides, which increase the hardness of the alloy. Complementary elements can be boron and silicon, which serve primarily for better melting and coating in the method of High-Velocity Oxygen Fuel (HVOF). Boron provides a lower melting point for better melting of the powder in the combustion chamber. Silicon, on the other hand, improves the spontaneous flow of molten particles in the outlet nozzle. [3] [5] [13]

\begin{tabular}{|c|c|c|c|c|c|c|c|}
\hline NiCrBSi & $\mathbf{C}$ & Ni & Cr & Si & B & Fe & O \\
\hline wt [\%] & 0,76 & Base & 15,16 & 4,65 & 3,19 & 3,87 & 0,043 \\
\hline
\end{tabular}

Table 1. Chemical composition of NiCrBSi [13]

The most modern method that can be used to make a NiCrBSi coating is the method of High-V0elocity Oxygen Fuel (HVOF). Compared to plasma spraying, the output speed at HVOF is 3 times higher. The melting temperature is a maximum of $5000{ }^{\circ} \mathrm{C}$, so there will be no significant changes in the structural and chemical composition as in the case of using the plasma. With a high output velocity of almost $1000 \mathrm{~m} / \mathrm{s}$, a very high coating quality with very low porosity and high adhesion to the base material exceeding $90 \mathrm{MPa}$ can be achieved. In thermal spraying, even with the correct choice of process conditions, the compressive stress between the molten coating grains can also be measured. This has a positive effect on the resistance to cracking and on the overall service life of the thermal spray. [2] [5] [13]

\subsection{Methodology of the experiment}

After considering all aspects, a semi-finished product (Fig. 3) with dimensions $\varnothing 100$ and length $500 \mathrm{~mm}$ was designed from material 12050 according to ČSN (C45 steel). The semi-finished product was divided by four notches with a width of $10 \mathrm{~mm}$. In this way, four surfaces with a length of $100 \mathrm{~mm}$ and a clamping part with a width of $60 \mathrm{~mm}$ were created. To ensure the rigidity of the system during machining, a centre hole is made at both ends of the semifinished product for clamping the chuck - tip.

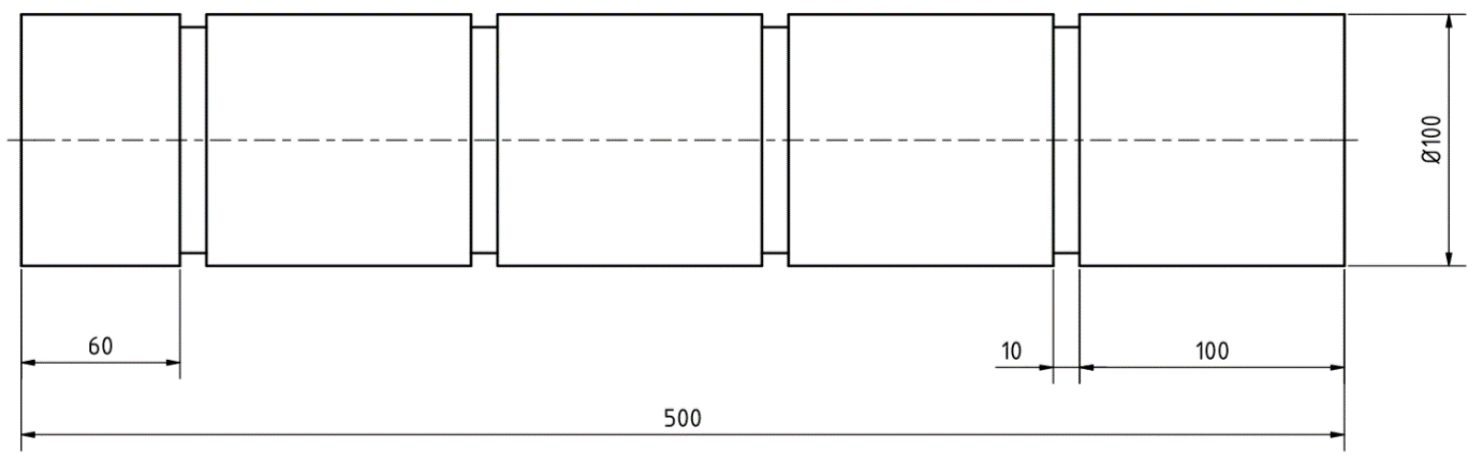

Fig. 3. The semi-finished product design

After the production of four semi-finished products according to the specified dimensions, an expedition to the Plasmametal company followed, where the thermal spray "NiCrBSi" with a thickness of $0.5 \mathrm{~mm}$ was applied using the HVOF method. The semi-finished product with thermal spray had a final dimension of $\varnothing 101-500 \mathrm{~mm}$.

Thermal spraying is generally very difficult to machine due to the special combination of elements. Due to the high strength and abrasive effects, it is necessary to choose materials with higher hardness and abrasion resistance. The following materials were selected for NiCrBSi thermal spraying.

- $\quad$ SC IC20 - type insert - SCMW 120408

- PCBN 0 - type insert - SCMW 120405 (45\% Cubic Boron Nitride)

- $\quad$ PCBN 1 - type insert - SCMW 120405 (90\% Cubic Boron Nitride)

- CVD - D - type insert - SCMW 120405 (Chemical Vapor Deposition of Diamond) 
The specific shape of the tool was designed to be used for turning (with the possibility of quickly replacing the worn insert during the process), but also for milling. The construction of the tool is unique in its placement of the insert with respect to the tool axis. The insert edge is not positioned in the tool axis but is inclined at an angle of $30^{\circ}$. With this inclined, it is possible to machine with a linear cutting edge using the entire length of the cutting edge.

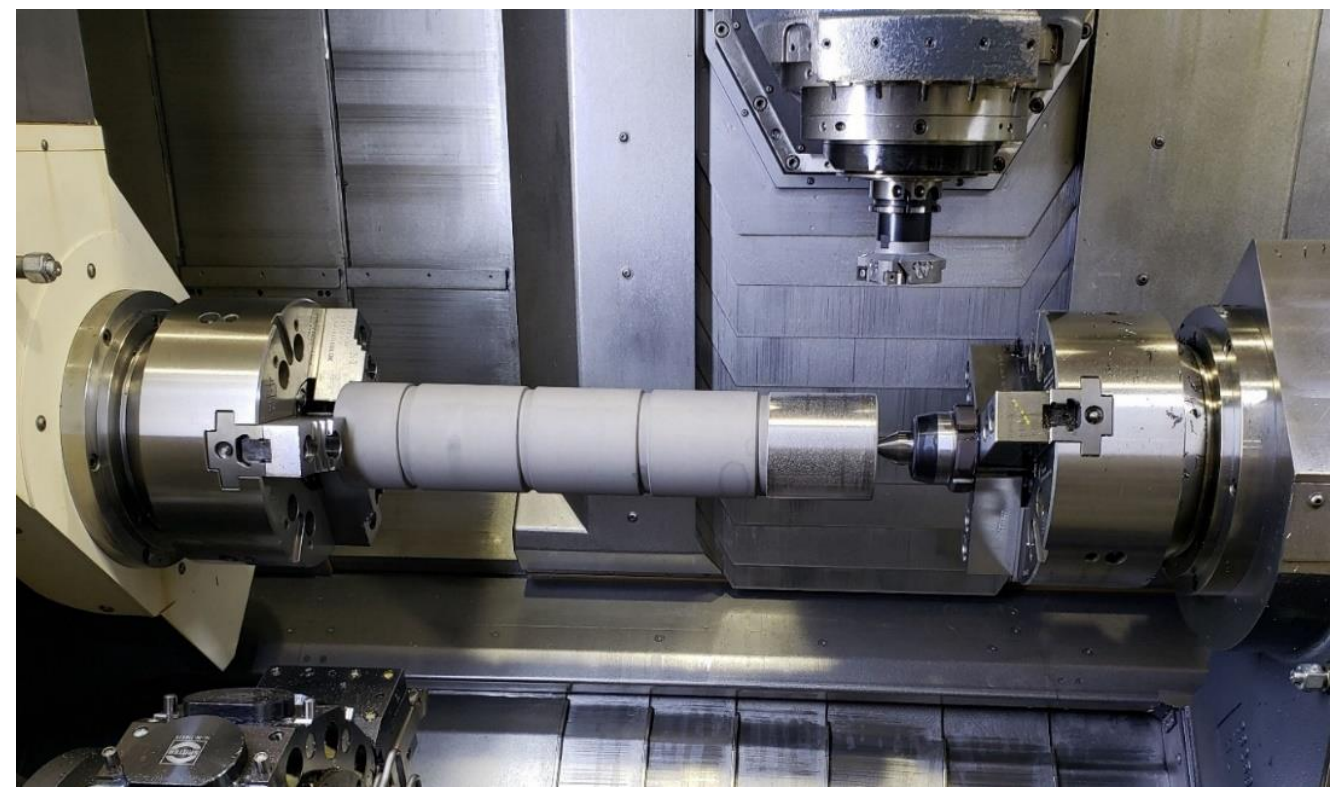

Fig. 4. The course of the experiment in the CTX Beta $1250 \mathrm{TC}$

During the machining process, the goal was to find suitable cutting conditions for the three types of cutting materials. The insert is positioned in the tool with a Rake angle $\gamma=0^{\circ}$ and a cutting angle $\lambda \mathrm{s}=70^{\circ}$. During machining, a fixed depth of cut was determined with a value of ap $=0.15 \mathrm{~mm}$. Variable conditions are cutting speed, feed per revolution and cooling. The effect on the roughness value of the machined surface Ra was investigated.

\section{The course of the experiment and evaluation}

\subsection{The experiment}

At the beginning of the experiment, several test cuts were made to determine the approximate machining conditions for each cutting material (Fig 5). When testing the SC IC20 insert, there was a problem with vibrations, which could only be eliminated by increasing the feed. However, the feed rate value has a significant effect on the roughness value, but vibrations significantly worsen the roughness, geometric tolerances and even stop the machine due to overload. When testing PCBN inserts, the brazed cutting edge was often chipped, probably due to high cutting forces. To reduce the cutting forces, the HSC mode with a cutting speed of 500 and $800 \mathrm{~m} / \mathrm{min}$ was also tested. However, in the HSC mode, the thermal spray was torn out, see Figure 6 . The best results were obtained using the CVD-D insert also with a brazed cutting edge. Roughness values ranged from $\mathrm{Ra}<1 \mu \mathrm{m}$, in two cases even $\mathrm{Ra}<0.25 \mu \mathrm{m}$, see Figure 7 .

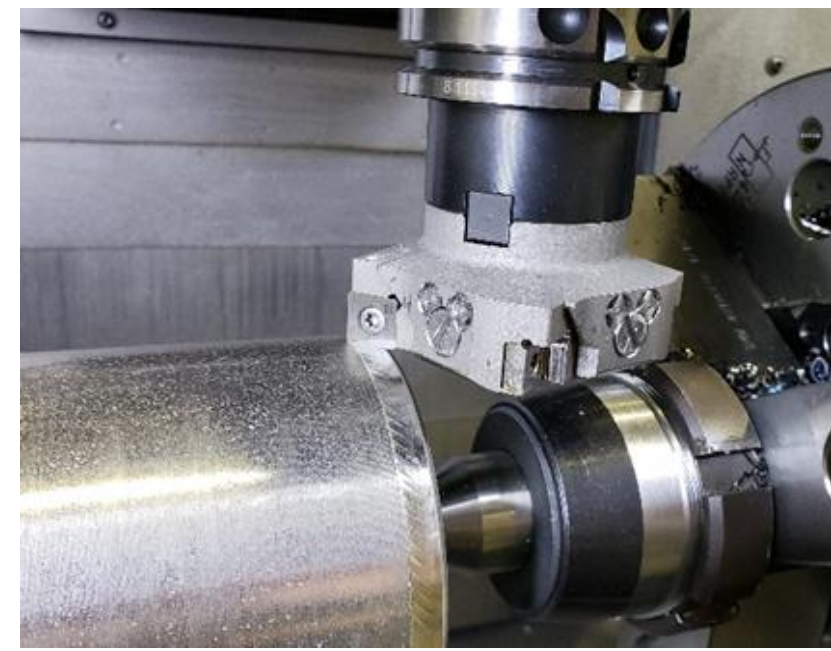

Fig. 5. Course of test cuts

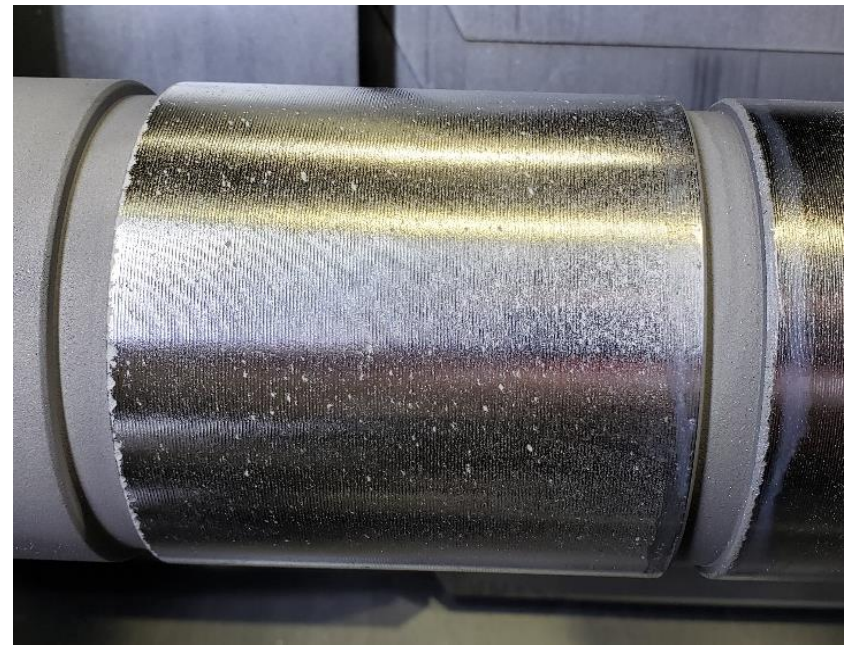

Fig. 6. Torn out coating particles 


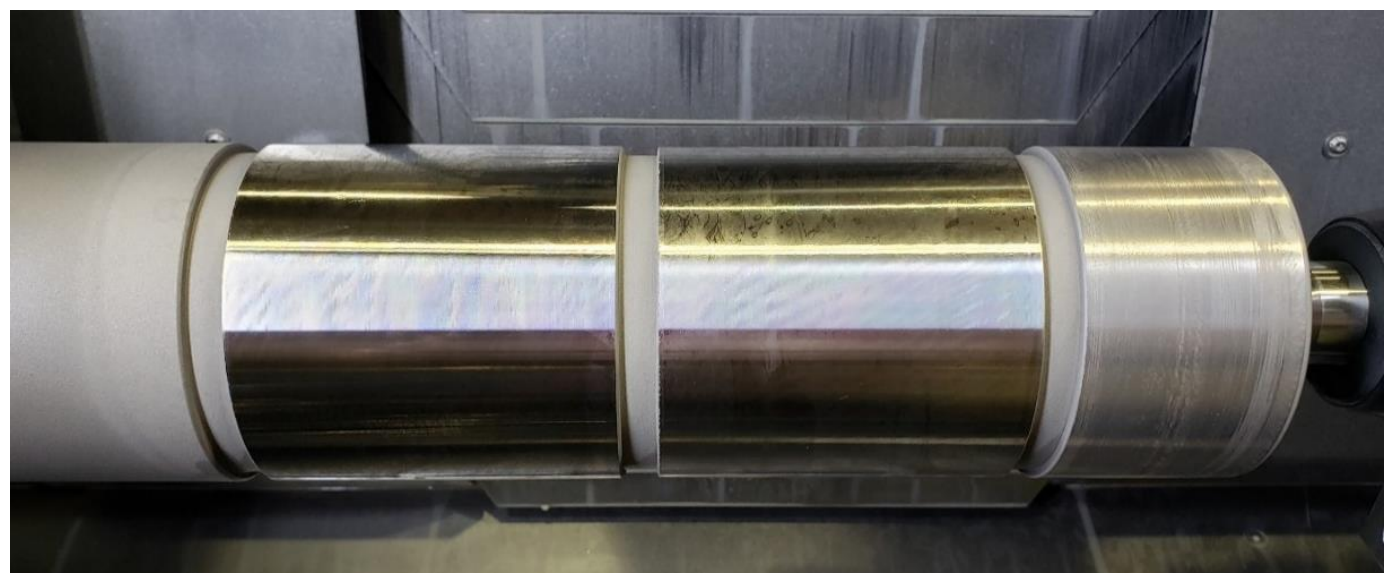

Fig. 7. Machined surface using CVD-D diamond insert in test numbers 12 and 13

\subsection{Evaluation of the Ra parameter}

The roughness parameter Ra was measured on a Hommel Etamic T8000 according to DIN EN ISO $4288: 1998$ norm. From the measured values it was found that very good roughness $\mathrm{Ra} \leq 1.6 \mu \mathrm{m}$ was achieved in several workpieces with different combinations of cutting speed, feed and cooling. The best result was achieved with workpiece No. 12 and No. 13 with a roughness value $\mathrm{Ra}<0.25 \mu \mathrm{m}$.

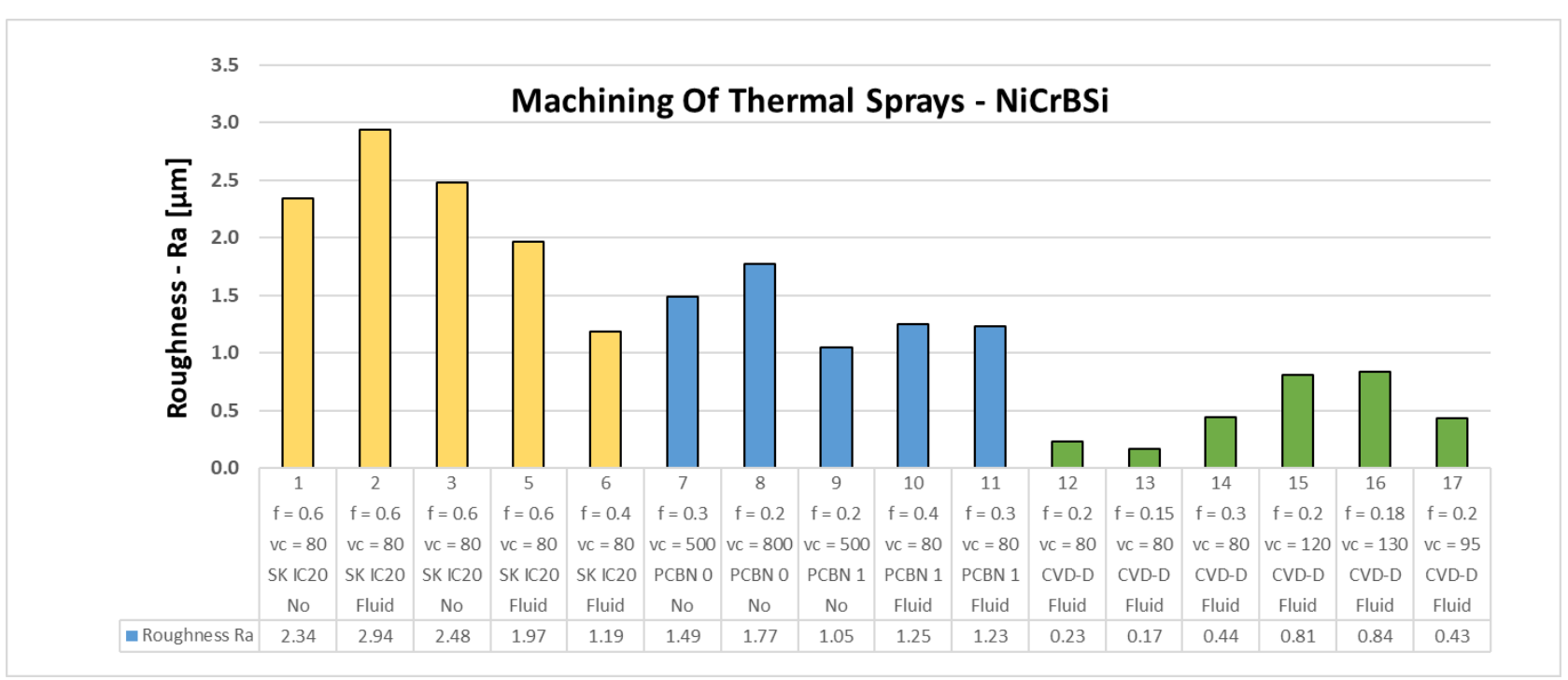

Graph 1. Dependence of cutting conditions on the roughness of the machined surface

\section{Conclusion}

At present, thermal sprays are machined using grinding technology due to their high hardness. The main goal of this research is to replace grinding technology with turning technology. The advantage of this change is the higher productivity of machining. At the beginning of this research, it was first necessary to find out whether we are able to obtain the same surface quality result as after grinding by the method of turning. After performing several test cuts, testing of individual cutting materials with varied cutting conditions began. After each machining of the specified length of $100 \mathrm{~mm}$, the surface roughness Ra was measured.

Of the materials tested, the best result was CVD-D (diamond). When testing samples 12 and 13, a surface roughness $\mathrm{Ra}<0.25 \mu \mathrm{m}$ was achieved. When machining under these conditions, the same cutting edge of the insert was used, as no wear was measured during the first two passes. After machining sample number 13, the cylindricality was measured with a value of $0.06 \mu \mathrm{m}$ and the roundness with a value of $0.03 \mu \mathrm{m}$. Average results were obtained with a PCBN insert, where the best roughness around $\mathrm{Ra}=1 \mu \mathrm{m}$ was achieved. However, during testing, the cutting edge was often chipped when compared to other types of inserts. When testing the HSC mode, the machined surface was significantly torn out, see Figure 6. The worst results were obtained when machining with the SC IC20 insert. The higher roughness was mainly due to the higher set feed $\mathrm{f}>0.5 \mathrm{~mm} / \mathrm{rev}$. When lower feeds were set, intense vibration occurred during machining, which worsened the roughness and geometric tolerances. After obtaining these results, we concluded that it is possible to replace grinding technology with turning technology. Now is the time to focus on long-term machining tests and the possibility of applying this research in practice. 


\section{Acknowledgments}

This article was created under the project SGS-2019-008: Research and Development for Innovation in the Field of Manufacturing Technology - Machining Technology III.

\section{References}

[1] Hoesel, D.; Wertheim, R.; Haenel, T. \& Thurner, S. (2011). Milling of Cast Material and PTA-Hard-Facing Layers of the Cobalt-Base-Alloy Stellite 12, Annals of DAAAM for 2011 \& Proceedings of the 22th International DAAAM Symposium, Published by DAAAM International, Vienna, 2011, ISBN 978-3-901509-83-4

[2] Houdkova, S., Vostrak, M. (2013). Comparison of NiCrBSi Coatings, HVOF Sprayed, Re-melted by Flame and by High-Power Laser. Available from: http://metal2013.tanger.cz/files/proceedings/12/reports/1407.pdf, Accessed: 2020-08-08

[3] http://www.ctemag.com/aa_pages/2011/110205-Grinding.html, (2011). High Velocity Grind, Accessed: 2020-0808

[4] Zaman, H. A.; Sharif, S.; Kim, D. W.; Idris, M. H.; Suhaimi, M. A. \& Tumurkhuyag, Z. (2017). Machinability of Cobalt-based and Cobalt Chromium Molybdenum Alloys - A Review, Procedia Manufacturing, Volume 11, Pages 563-570, ISSN 2351-9789, Available from: https://doi.org/10.1016/j.promfg.2017.07.150.

[5] Cesanek, Z. (2015). Thermally Sprayed Coatings Used in Corrosive Environments, Ph.D. Dissertation, ZCU, FST, Pilsen, Czech republic

[6] https://www.triboing.cz/zarove-nastriky.html, (2018). Thermal sprays, Tribo Engineering, Accessed: 2020-08-08

[7] Rehor, J. (2016). Theory of Machining. ZCU in Pilsen [Internal documentation], Accessed: 2020-08-08

[8] Zhang, P., Zhanqiang, L., Du, J. (2020). On machinability and surface integrity in subsequent machining of additively - manufactured thick coatings, Journal of Manufacturing Processes (53:123-143) DOI: 10.1016/j.jmapro.2020.02.013

[9] Hajdarevic, D. B.; Cekic, A. \& Kulenovic, M. (2014). Experimental Study on the High Speed Machining of Hardened Steel, Annals of DAAAM for 2014 \& Proceedings of the 25th International DAAAM Symposium, Published by DAAAM International, Vienna, 2014, pp. $291-295$.

[10] Farsky, J. (2019). Grinding Inconel 718 Using a Galvanic Grinding Wheel. Proceedings 2019, page numbers (127132), DOI: 10.1007/s13369-014-1343-9, ISBN 978-80-261-0860-3.

[11] Farsky, J.; Baksa, T. \& Zetek, M. (2018). Influence of Grinding Parameters on Forces when Grinding Maraging Steel X3Nicomo 1895 with SiC Grinding Wheels; Proceedings of the 29th International DAAAM Symposium 2018. DAAAM International Vienna, 2018, s. 0767-0771. DOI: 10.2507/29th.daaam.proceedings.111.

[12] https://www.plasmametal.cz/pouzite-technologie, (2019). Thermal spraying. Plasmametal, Accessed: 2020-08-08

[13] Liu, J., Wang, Y., Li, H. (2017). Numerical and experimental analysis of thermal and mechanical behavior of NiCrBSi coatings during the plasma spray process. Journal of Materials Processing Technology, DOI: 10.1016/j.jmatprotec.2017.06.025 